\title{
Prison Guards' Attitudes Towards the Prevention of Sexual Contacts Between Inmates
}

\author{
CLÁUDIA COELHO and RUI ABRUNHOSA GONÇALVES \\ Cláudia Coelho is Assistant Researcher and PhD Student, School of Psychology, \\ University of Minho, Portugal; Rui Abrunhosa Gonçalves is Associate \\ Professor, School of Psychology, University of Minho, Portugal
}

\begin{abstract}
This article presents the main findings of an innovative Portuguese research project on prison guards' attitudes towards the prevention of sexual contacts between inmates. Sexuality in prisons is still a poorly-studied issue, although its increasing visibility demands a better understanding of prison dynamics. Results show that guards hold very favourable attitudes towards the prevention of forced sexual contacts between inmates, but they are more ambiguous concerning consensual sexuality. This result is influenced by the characteristics of the inmates under the guards' supervision and by the prison guards' knowledge of the existence of sexual contacts between inmates. The results will be discussed, along with their impact on the development of training programmes and policies regarding sexual contacts between inmates.
\end{abstract}

Keywords: attitudes; inmates; prison guards; sexuality

Only recently has sexuality in prisons attracted the attention of the scientific community. In fact, until 1980 very few authors studied this issue consistently. Besides, most of the studies developed so far focused on characterising the prevalence of sexual contacts between inmates or on alerting one to the transmission of diseases subsequent to unprotected sex in prison, without studying more thoroughly, prison dynamics and the role of its multiple actors (Tewksbury and West 2000).

Gradually, awareness regarding this issue has increased due to concerns with the safety and health of both the inmate population and the professionals working in correctional facilities. In fact, sexuality can be related to prison violence (irrespective of whether or not it is associated with sexual aggression) because power and control dynamics, as well as situations of jealousy or infidelity, can be present in the context of consensual relationships, increasing the risk for potential conflict. This is even more alarming because of inmates' propensity to be more violent than the average individual (Gonçalves in press).

In Portugal, as in many other countries, there are no death penalties or life sentences. Therefore, most inmates will return to their communities and it 
cannot be expected that experiences gained in prison will be completely left behind. It is likely that incidents of violence and trauma in prison will influence ex-inmates, eventually increasing their violent behaviour (Corlew 2006). This situation, along with the possible infection with sexually transmitted diseases while incarcerated, constitutes a risk not only for the inmates themselves, but also for their partners and for society as a whole.

Since prison guards are professionals who have direct contact with inmates and are assigned tasks of surveillance, protection and rehabilitation, the purpose of this research is to ascertain their attitudes concerning the prevention of sexual contacts between inmates. Furthermore, considering stereotypes and idiosyncrasies involving sex offenders, it is also appropriate to compare prison guards working in institutions characterised by high numbers of sex offenders with those supervising more randomly-distributed inmates.

\section{Literature Review}

In the following sections, dynamics and prevalence pertaining to inmate sexuality will be analysed, with a special emphasis on forced sexual contacts due to its increased individual and institutional impact. Although we acknowledge the relevance of this issue among female inmate populations, this study focuses only on male inmates.

Moreover, the prison system plays an important role in the prevention of sexual contacts between inmates, as well as in the intervention with both victims and offenders. However, it can also be responsible for the promotion of attitudes and behaviours that legitimise and facilitate sexual offences between inmates. Therefore, this will also be analysed, along with the role of prison guards, as these staff members work closely with inmates and are, therefore, more able to influence their attitudes and behaviours.

\section{Sexual Contacts Between Inmates}

Research findings on consensual sexual contacts between inmates have been divergent so far. Prevalence found by Nacci and Kane (1983) ranged from $12 \%$ to $30 \%$, and $19 \%$ of Tewksbury's (1989) sample admitted being involved in consensual sexual practices. However, Saum et al. (1995) found much smaller prevalence, with only $2 \%$ of the inmates disclosing their participation in consensual sexual contacts with other inmates.

These results seem to reflect the difficulty in studying consensual sexuality in prison rather than the reality. In fact, methodological and conceptual variables (Hensley and Tewksbury 2002), along with individual differences in the inmate population might explain such disparities (Hensley, Koscheski and Tewksbury 2005). Furthermore, it is not always easy to distinguish consensual and forced sexual contacts, specifically when covert strategies of coercion are used (Eigenberg 2000a). These complexities also exist and might be aggravated in the research on forced sexual contacts between inmates (Jones and Pratt 2008). 
Despite the fact that most research regarding sexual victimisation in prison was developed after the 1980s, pioneer studies have been conducted since 1930, allowing a better understanding of prison dynamics concerning attitudes towards victims and offenders. Actually, these studies focused on illustrating how prison sexuality was responsible for the definition of hierarchies among inmates: those who were forced to have sex were described as punks and despised by other inmates; those who sexually victimised others were named wolves and occupied the top of the hierarchy due to their displays of masculinity through aggression; and those who willingly engaged in homosexual contacts were labelled fags and placed in the middle of the pyramid (cf. Eigenberg 1992). Regardless of some recent changes in this hierarchy, as pointed out by Hensley et al. (2003), the major idea remains the same: victims are weak and should not be tolerated, while aggressors are strong and should be admired.

These first studies supported the perspective of situational homosexuality (Ibrahim 1974), justifying consensual and forced sexual contacts between inmates through their deprivation of heterosexuality, without any further distinction between victims and offenders. Therefore, despite the identification of a hierarchy based on sexual behaviour, the power and control dynamics associated with forced sex in prison were yet to be acknowledged. However, as Knowles (1999) underlines, forced sex in prison results from a desire to acquire or express power through the domination and humiliation of victims who, according to the prison culture, lose their masculinity and become the offenders' property.

Examining research on the incidence of forced sexual contacts between inmates, it is possible to observe that results range from $0.3 \%$ (Nacci and Kane 1983) to $22 \%$ (Struckman-Johnson et al. 1996). However, comparison of results is undermined due to conceptual issues. Some authors only consider situations of rape in their studies, others include undesired fondling and kissing or coercion to get sexually involved, while others focus solely on the undesired nature of sexual contacts (Jones and Pratt 2008).

The study of Struckman-Johnson and colleagues (1996) using a sample of 474 subjects, deserves special mention as it is, so far, the only one replicated, revealing that $22 \%$ of the subjects had been sexually victimised. The subsequent study, carried out in seven prisons with 1,788 participants, found an average of $21 \%$ of inmates who were sexually victimised (Struckman-Johnson and Struckman-Johnson 2000). Nevertheless, more recent studies achieved lower results, ranging between $1.6 \%$ (Wolff et al. 2006) and 2.1\% (Human Rights Watch 2007). This decrease may possibly be an outcome of the successful implementation of the Prison Rape Elimination Act in 2003.

Regardless of the number of studies developed in the United States concerning this subject, as well as those carried out in other countries like South Africa (Gear 2007), the United Kingdom (Banbury 2004), Germany (Kury and Smartt 2002), Venezuela (Salas 2001), Israel (Einat and Einat 2000) and Taiwan (Hsu 2005), in Portugal this issue was only marginally addressed in another study about general prison violence (see Gonçalves in press). 


\section{The Role of Prison Guards}

Prison guards work in one of the most hostile settings. It is their duty to maintain security amid violent individuals incarcerated against their will, to prevent escapes, to assure prison routines and to supervise inmates' behaviour. Gradually, prison guards were also expected to develop rehabilitative tasks, which sometimes are incompatible with other more impersonal functions. Meanwhile, prison guards are confronted with popular culture describing them as corrupt abusers of power, who indiscriminately use violence (Crawley and Crawley 2008; Eigenberg and Baro 2003).

Considering the problem of sexual contacts between inmates, it must be recognised that prison guards' attitudes and behaviours can be understood as part of a continuum, with those who try to protect potential victims and co-operate in the implementation of preventive programmes at one end, and those who sexually abuse inmates or directly contribute to a rapeprone culture at the other (Eigenberg 2000a). Somewhere in the middle can be found those guards who do not contribute directly to the existence of abuse in prison but tolerate it, making no effort to protect victims or to punish perpetrators.

Dumond (2000) underlines that even though most prison staff do not sexually abuse inmates, indirect forms of sexual victimisation are somewhat common, like the threat of making an inmate an easy target for sexually-aggressive inmates (Eigenberg 2000a) or the deliberate indifference to specific conditions that increase inmates' vulnerability (for example, being homosexual, transsexual or a sex offender - particularly a child molester) (Man and Cronan 2001).

It is disturbing that in Eigenberg's (1989) research, about half of the prison guards believed that inmates who had previously been involved in consensual sexual contacts with other inmates deserved to be raped and that an inmate's individual characteristics would influence his credibility as a victim. In fact, and despite the increased vulnerability of homosexual inmates, prison guards tend to be reluctant to protect them, assuming they willingly engage in sexual practices with other inmates. Similarly, even though in some prisons protective measures can be applied to convicted sex offenders, this group is still at greater risk due to negative attitudes shared by other inmates and prison staff (Hogue 1993).

In a more recent study, most guards already identified as forced sexual contacts situations in which covert coercion strategies were used (Moster and Jeglic 2009). However, there were coercive conditions (for example, sex in exchange for protection) that $20 \%$ of the guards still did not evaluate as assault. Nevertheless, most prison guards recognised the importance of institutional policies, staff training and supervision as effective measures in preventing forced sexual contacts between inmates.

Prison guards' perceptions and attitudes are extremely important because of the potential to impact on their behaviours. Regardless of their willingness and obligation to prevent sexual contacts between inmates through surveillance, disciplinary proceedings and encouragement of reports, many guards are less motivated to act when sexuality is identified 
as consensual and it is not always easy to distinguish between consensual and forced sexual contacts (Eigenberg 2000a). For instance, if prison guards consider that forced sex inevitably implies the use of direct violence, it is likely that they will not try to prevent or punish sexual contacts that rely on threats, coercion and blackmail, eventually considering them consensual (Eigenberg 2000b).

Sexual contacts between inmates are part of prison life and prison guards play an important role in its prevention. For that reason they should receive suitable training to increase their awareness of prison dynamics involving sexual contacts between inmates and to make them able to act appropriately in such situations.

\section{Method}

Aims

The general aims of this study are to evaluate prison guards' attitudes towards the prevention of sexual contacts between inmates and to identify the influence of demographic and professional variables on these attitudes. More specifically, this study aims to test the following hypotheses:

1. The majority of prison guards have favourable attitudes towards the prevention of sexual contacts between inmates, especially when they result from victimisation.

2. Prison guards' attitudes towards the prevention of sexual contacts between inmates are not influenced by age, professional experience, qualifications or the number of prisons in which they have worked previously.

3. Prison guards' knowledge of the existence of sexual contacts between inmates influences their attitudes towards the prevention of such behaviours.

4. Working in prisons with a high number of sex offenders influences prison guards' attitudes towards the prevention of sexual contacts between inmates.

Because of the exploratory nature of this study, our main purpose was to identify the possible influence of certain variables on prison guards' attitudes towards the prevention of sexual contacts between inmates. Thus, no predictive analysis was conducted.

\section{Participants}

Prison guards were requested to participate in this study which took place in Portuguese prison facilities from the northern and central regions, between April and September 2007.

A total of 400 survey questionnaires were distributed and 199 were returned, making the response rate $49.8 \%$. From the 199 prison guards who agreed to participate in the study, three were removed from the sample because many scale items were unanswered, along with four female prison guards removed because of their lack of representativeness as a 
study variable. From the remaining 192 male prison guards, 159 (82.8\%) were working in prisons with a normal distribution of inmates' criminal typologies and only $33(17.2 \%)$ were working in prisons with a high number of sex offenders.

The average age of the participants was 37.0 years $(S D=8.0)$ and agegroups were created based on the mean and standard deviation. Most of the participants were aged between 30 and 37 years (54.6\%), married or living together $(73.6 \%)$, with qualifications between the 9th and 11th grades $(53.1 \%),{ }^{1}$ with professional experience of eleven years or less $(63.5 \%)$, and having worked in fewer than three prisons $(40.4 \%)$. The Prison Guards' Union was contacted in order to establish the representativeness of our sample, but no answer was received.

\section{Measures}

The dependent variable was the prison guards' attitude towards the prevention of sexual contacts between inmates and it was measured by scores from a translated and adapted research version of Eigenberg's (2000a) Attitude Scale about Consensual and Forced Sexual Contacts (ASCFSC). It is a ten-item Likert scale, ranging from ' $1=$ totally disagree' to ' $6=$ totally agree'.

A principal axis factoring with orthogonal rotation indicated two robust factors, no cross-loadings and adequate internal consistencies. These two factors included five items each, accounted for $49.43 \%$ of the variance and, based on the content of the items, the factors were labelled: (1) 'Attitudes towards the prevention of consensual sexual contacts between inmates' (\% of variance $=26.70$; Cronbach's $\alpha=0.85$ ); and (2) 'Attitudes towards the prevention of forced sexual contacts between inmates' (\% of variance $=22.73$; Cronbach's $\alpha=0.77$ ) (see Table 1).

Total scores range from 10 to 60 and factorial scores range from 5 to 30 , with higher scores pointing to more favourable attitudes towards the prevention of sexual contacts between inmates. Originally, no information was available concerning the existence of cut-points on this scale (Eigenberg 2000a).

Two questions were also asked to assess prison guards' awareness of the existence of sexual contacts between inmates in facilities where they had previously worked and to quantify these contacts: (i) 'Were you aware of the existence of consensual sexual contacts between inmates in prisons where you worked? If so, how many times?'; and (ii) 'Were you aware of the existence of forced sexual contacts between inmates in prisons where you worked? If so, how many times?'.

\section{Data Analysis}

Data analysis employed SPSS 16.0 for Windows. When the conditions required for the use of parametric tests were not present but the results obtained with non-parametric tests were similar, parametric tests were used. 
TABLE 1

Factor Loadings for the Attitude Scale about Consensual and Forced Sexual Contacts

\begin{tabular}{|c|c|c|c|}
\hline \multirow[t]{2}{*}{ Items } & & \multicolumn{2}{|c|}{ Factors } \\
\hline & & 1 & 2 \\
\hline 1 & $\begin{array}{l}\text { Guards should do everything they can to prevent consensual sexual } \\
\text { contacts between inmates }\end{array}$ & 0.85 & 0.13 \\
\hline 2 & $\begin{array}{l}\text { Guards should do everything they can to prevent sexual assaults } \\
\text { between inmates }\end{array}$ & 0.16 & 0.72 \\
\hline 3 & $\begin{array}{l}\text { Guards should patrol areas frequently to prevent consensual sexual } \\
\text { contacts between inmates }\end{array}$ & 0.72 & 0.26 \\
\hline 4 & $\begin{array}{l}\text { Guards should patrol areas frequently to prevent sexual assaults } \\
\text { between inmates }\end{array}$ & 0.14 & 0.75 \\
\hline 5 & $\begin{array}{l}\text { Guards should issue disciplinary reports to inmates who participate in } \\
\text { consensual sexual contacts }\end{array}$ & 0.72 & 0.15 \\
\hline 6 & $\begin{array}{l}\text { Guards should issue disciplinary reports to inmates who pressure other } \\
\text { inmates for sex }\end{array}$ & 0.14 & 0.64 \\
\hline 7 & $\begin{array}{l}\text { Guards should encourage inmates to report consensual sexual contacts } \\
\text { between inmates }\end{array}$ & 0.60 & 0.07 \\
\hline 8 & $\begin{array}{l}\text { Guards should encourage inmates to report sexual assaults between } \\
\text { inmates }\end{array}$ & 0.03 & 0.69 \\
\hline 9 & $\begin{array}{l}\text { Guards should talk to inmates about consensual sexual contacts } \\
\text { between inmates, so they don't engage in it }\end{array}$ & 0.68 & 0.10 \\
\hline 10 & Guards should talk to inmates about the risk of sexual assault & 0.13 & 0.42 \\
\hline
\end{tabular}

(Note: A threshold of 0.40 was considered for assigning items to each factor. Loadings of items in each factor clearly distinguish a first factor accounting for 'consensual sexual contacts between inmates' (items 1, 3, 5, 7 and 9) from a second factor accounting for 'forced sexual contacts between inmates' (items 2, 4, 6, 8 and 10).)

\section{Results}

Hypothesis 1 predicted that the majority of prison guards had favourable attitudes towards the prevention of sexual contacts between inmates, especially when they are the result of victimisation, which is totally confirmed. Considering that scores could range between 10 and 60, results show that prison guards have favourable attitudes towards the prevention of general sexual contacts between inmates $(M=43.89, S D=8.42)$. Scores concerning attitudes towards the prevention of consensual and forced sexual contacts between inmates could range between 5 and 30 . Results illustrate that although prison guards have favourable attitudes towards the prevention of both kinds of sexual contacts, they are significantly more willing to prevent those that are forced $(M=26.24, S D=3.81)$ when compared with those that are consensual $(M=17.65, S D=6.43)$ $(t[191]=-18.61, p<0.001)$.

According to hypothesis 2, prison guards' attitudes regarding the prevention of sexual contacts between inmates were not influenced by age, professional experience, qualifications or the number of prisons where guards had previously worked, which has been confirmed. Concerning the variable 'age', scores for attitudes towards the prevention of general 
$(F[3,179]=0.77, \quad \mathrm{~ns}), \quad$ consensual $\quad(F[3,179]=2.01, \quad \mathrm{~ns})$ and forced $(F[3,179]=2.05, \mathrm{~ns})$ sexual contacts between inmates did not reveal any statistical significance. Taking prison guards' professional experience as an independent variable, no significant statistical effects were found on the scores for attitudes towards the prevention of general $(F[2,175]=0.76, \mathrm{~ns})$, consensual $(F[2,175]=2.08$, ns) and forced $(F[2,175]=1.59$, ns $)$ sexual contacts between inmates. Similar results were found when the independent variable was prison guards' qualifications: they have no effect on their attitudes towards general $(F[2,172]=1.43$, ns $)$, consensual $(F[2,172]=3.07$, $\mathrm{ns})$ and forced $(F[2,172]=0.49, \mathrm{~ns})$ sexual contacts between inmates. Finally, prison guards' attitudes towards general, consensual and forced sexual contacts between inmates were not influenced by the number of prisons where guards had previously worked $((F[2,175]=1.04, \mathrm{~ns}),(F[2,175]=0.78$, ns), $(F[2,175]=0.78, \mathrm{~ns})$, respectively) (see Table 2$)$.

Hypothesis 3 predicted that prison guards' knowledge of the existence of sexual contacts between inmates influenced their attitudes towards the prevention of such behaviours. Nearly three-quarters $(74.2 \%)$ of the guards admitted being aware of the existence of consensual sexual contacts between inmates but only about half of them were able to estimate the number of consensual sexual contacts they were aware of. Most of the guards $(37.5 \%)$ were aware of one or two cases, while $30.6 \%$ knew of three or four cases and $31.9 \%$ knew of five or more consensual sexual contacts between inmates. As for forced sexual contacts between inmates, $52.1 \%$ of the guards acknowledged their existence, but again only about half of them were able to quantify their occurrence, with $33.3 \%$ being aware of one situation of forced sexual contacts between inmates, $31.3 \%$ of two, $18.5 \%$ of three or four and $16.7 \%$ of five or more. Statistical analysis revealed that only prison guards' attitudes towards the prevention of forced sexual contacts between inmates were influenced by prison guards' knowledge of the existence of consensual $(t[188]=2.31, p<0.05)$ and forced $(t[188]=2.10, p<0.05)$ sexual contacts between inmates. Guards who were aware of the existence of sexual contacts between inmates (whether consensual or forced) had more favourable attitudes towards the prevention of forced sexual contacts between inmates (see Table 3 ).

According to hypothesis 4, working in prisons with a high number of sex offenders influences prison guards' attitudes towards the prevention of sexual contacts between inmates. Results do not show an effect of the independent variable on prison guards' attitudes towards the prevention of consensual sexual contacts between inmates $(t[190]=-1.78$, ns). Conversely, this effect is present on prison guards' attitudes towards the prevention of general $(t[190]=-2.80, p<0.01)$ and forced $(t[190]=-3.18, p<0.01)$ sexual contacts, with guards supervising a high number of sex offenders having less favourable attitudes towards the prevention of these contacts (see Table 4).

\section{Discussion}

This study revealed that consensual and forced sexual contacts between inmates were known by nearly two-thirds and more than half of prison 
TABLE 2

Effect of Prison Guards' Demographic and Professional Variables on their Scores on ASCFSC

\begin{tabular}{|c|c|c|c|c|c|}
\hline \multicolumn{6}{|c|}{ Age } \\
\hline & $\begin{array}{l}\leq 29 \text { years } \\
(\mathrm{N}=24) \\
M(S D)\end{array}$ & $\begin{array}{c}30-37 \text { years } \\
(\mathrm{N}=100) \\
M(S D)\end{array}$ & $\begin{array}{c}\text { 38-45 years } \\
(\mathrm{N}=26) \\
M(S D)\end{array}$ & $\begin{array}{l}\geq 46 \text { years } \\
(\mathrm{N}=33) \\
M(S D)\end{array}$ & $F[3,179]$ \\
\hline Total & $42.25(7.86)$ & $44.20(7.85)$ & $42.86(9.48)$ & $45.27(9.61)$ & 0.77 (ns) \\
\hline Consensual & $16.67(6.08)$ & $17.36(6.18)$ & $17.12(6.68)$ & $20.09(6.22)$ & $2.01(\mathrm{~ns})$ \\
\hline Forced & $25.58(3.08)$ & $26.84(3.71)$ & $25.74(4.44)$ & $25.18(4.08)$ & $2.05(\mathrm{~ns})$ \\
\hline \multicolumn{6}{|c|}{ Professional experience } \\
\hline & $\begin{array}{c}\leq 11 \text { years } \\
(\mathrm{N}=113) \\
M(S D)\end{array}$ & $\begin{array}{r}12-2 \\
(\mathrm{~N} \\
M\end{array}$ & $\begin{array}{l}\text { years } \\
37) \\
D D)\end{array}$ & $\begin{array}{l}\geq 22 \text { years } \\
(\mathrm{N}=28) \\
M(S D)\end{array}$ & $F[2,175]$ \\
\hline Total & $43.41(8.03)$ & 45.39 & $(8.91)$ & $44.00(9.52)$ & $0.76(\mathrm{~ns})$ \\
\hline Consensual & $17.00(6.22)$ & 18.97 & $(6.32)$ & $19.00(6.32)$ & $2.08(\mathrm{~ns})$ \\
\hline Forced & $26.42(3.71)$ & 26.41 & $(4.25)$ & $25.00(3.89)$ & $1.59(\mathrm{~ns})$ \\
\hline \multicolumn{6}{|c|}{ Qualifications } \\
\hline & $\begin{array}{c}<9 \text { th grade } \\
(\mathrm{N}=23) \\
M(S D)\end{array}$ & $\begin{array}{r}=9 \text { th and }< \\
(\mathrm{N}= \\
M(\end{array}$ & $\begin{array}{l}2 \text { th grades } \\
93) \\
D)\end{array}$ & $\begin{array}{c}\geq 12 \text { th grade } \\
(\mathrm{N}=59) \\
M(S D)\end{array}$ & $F[2,172]$ \\
\hline Total & $46.57(9.90)$ & 43.28 & $8.79)$ & $43.62(7.04)$ & 1.43 (ns) \\
\hline Consensual & $20.65(6.33)$ & 17.30 & $6.41)$ & $17.05(5.95)$ & $3.07(\mathrm{~ns})$ \\
\hline Forced & $25.91(4.75)$ & 25.98 & 4.06) & $26.58(3.14)$ & 0.49 (ns) \\
\hline \multicolumn{6}{|c|}{ Number of prisons } \\
\hline & $\begin{array}{c}<3 \\
(\mathrm{~N}=72) \\
M(S D)\end{array}$ & $\begin{array}{r}= \\
(\mathrm{N}= \\
M\end{array}$ & $\begin{array}{l}3 \\
65) \\
D)\end{array}$ & $\begin{array}{c}>3 \\
(\mathrm{~N}=41) \\
M(S D)\end{array}$ & $F[2,175]$ \\
\hline Total & $43.45(8.44)$ & 43.52 & $(9.33)$ & $45.66(7.06)$ & $1.04(\mathrm{~ns})$ \\
\hline Consensual & $17.54(6.16)$ & 17.29 & $(6.94)$ & $18.80(5.66)$ & $0.78(\mathrm{~ns})$ \\
\hline Forced & $25.91(4.17)$ & 26.23 & $(4.08)$ & $26.85(2.86)$ & $0.78(\mathrm{~ns})$ \\
\hline
\end{tabular}

guards, respectively, confirming that similar to other countries, this is a problematic issue in the Portuguese prison context (see, for example, Banbury 2004; Gear 2007; Hsu 2005; Human Rights Watch 2007; Kury and Smartt 2002; Wolff et al. 2006).

Prison guards showed favourable attitudes towards the prevention of sexual contacts between inmates, mostly when victimisation was involved, reproducing the results achieved by Eigenberg (2000a). However, tolerance regarding consensual sexual contacts between inmates can be a reason for concern, considering the association of sexual contacts between 
TABLE 3

Effect of Prison Guards' Knowledge of the Existence of Sexual Contacts Between Inmates on their Scores on ASCFCS

Awareness of consensual sexual contacts

\begin{tabular}{|c|c|c|c|}
\hline & $\begin{array}{c}\text { Yes } \\
(\mathrm{N}=141) \\
M(S D)\end{array}$ & $\begin{array}{c}\text { No } \\
(\mathrm{N}=49) \\
M(S D)\end{array}$ & $t[188]$ \\
\hline Total & $44.18(7.73)$ & $43.03(9.98)$ & $0.83(\mathrm{~ns})$ \\
\hline Consensual & $17.56(6.08)$ & $17.84(7.32)$ & $-0.27(\mathrm{~ns})$ \\
\hline Forced & $26.62(3.50)$ & $25.19(4.41)$ & $2.31 *$ \\
\hline \multicolumn{4}{|c|}{ Awareness of forced sexual contacts } \\
\hline & $\begin{array}{c}\text { Yes } \\
(\mathrm{N}=99) \\
M(S D)\end{array}$ & $\begin{array}{c}\mathrm{No} \\
(\mathrm{N}=91) \\
M(S D)\end{array}$ & $t[188]$ \\
\hline Total & $44.36(8.35)$ & $43.37(8.37)$ & $0.82(\mathrm{~ns})$ \\
\hline Consensual & $17.58(6.55)$ & $17.68(6.28)$ & $-0.11(\mathrm{~ns})$ \\
\hline Forced & $26.78(3.68)$ & $25.68(3.86)$ & $2.10^{*}$ \\
\hline
\end{tabular}

(Note: $* p<0.05$.)

TABLE 4

Effect of the Number of Sex Offenders Under Prison Guards' Supervision on their Scores on ASCFCS

\begin{tabular}{lccc}
\hline & $\begin{array}{c}\text { High number of } \\
\text { sex offenders } \\
(\mathrm{N}=33)\end{array}$ & $\begin{array}{c}\text { Normal distribution of } \\
\text { inmates' criminal typologies } \\
(\mathrm{N}=159)\end{array}$ & $t[190]$ \\
& $M(S D)$ & $M(S D)$ & \\
\hline Total & $40.21(9.29)$ & $44.65(8.05)$ & $-2.80^{* *}$ \\
Consensual & $15.85(5.95)$ & $18.02(6.48)$ & $-1.78(\mathrm{~ns})$ \\
Forced & $24.36(5.27)$ & $26.62(3.32)$ & $-3.18^{* * *}$ \\
\hline
\end{tabular}

(Note: $* * p<0.01$.)

inmates (consensual and forced) with increased violence inside prisons. In fact, many inmates are incarcerated for violent behaviour exhibited on the outside, which frequently reflects their lack of adequate problem-solving abilities. Romantic involvements and sexuality in prison, as in general society, can be a source of conflict that is dealt with using violence, by violent individuals.

Consensual sexuality between inmates should be an issue for further debate given the eventual conflict between individual and collective interests. In fact, imprisonment does not officially deny inmates' right to get sexually involved but, simultaneously, sexual contacts between inmates 
increase the likelihood of becoming a victim of violence for both inmates and correctional officers.

Therefore, prison guards' tolerance towards consensual sexual contacts between inmates can be a demonstration of respect for inmates' individual choices. However, it can also be a sign of embarrassment in addressing sexuality due to lack of training or it can reveal guards' difficulty in acknowledging the relationship between inmates' sexual contacts and violent behaviour.

Furthermore, one should question if evaluations of consensuality are accurate. As Eigenberg (2000a) underlines, the lack of obvious physical violence does not necessarily mean that inmates' sexual contacts are truly consensual, since threats, coercion or other more covert strategies can be used.

Demographic and professional variables did not influence prison guards' attitudes towards the prevention of sexual contacts between inmates, which can be a result not only of more general attitudes and beliefs regarding prisons and (homo)sexuality, but also evidence of respect for professional responsibilities and duties associated with surveillance and protection of inmates. Given that answers were anonymous and no benefits were associated, the influence of social desirability, though possible, seems unlikely.

Assuming that information might increase consciousness and eventually lead to attitude change, it was predicted in this study that prison guards' knowledge of the existence of sexual contacts between inmates would have an effect on their attitudes towards the prevention of such contacts, which has been confirmed only for attitudes towards the prevention of forced sexual contacts. This is probably a result not only of awareness and concern with the problem of forced sexual contacts, but also of acceptance of consensual sexual contacts, which brings us back to the previously-mentioned conflict of individual and collective interests and to the dilemma of evaluating consensuality.

The absence of a significant effect of the number of sex offenders under prison guards' supervision on their attitudes towards the prevention of consensual sexual contacts between inmates might, once again, be evidence of their tolerance towards these kind of contacts. Conversely, prison guards who work in facilities characterised by a more normal distribution of inmates' criminal typologies seem to have a more favourable attitude towards the prevention of forced sexual contacts, which might be explained through the presence of more negative attitudes towards sex offenders among those who supervise them. Hogue (1993) had mentioned that prison officers were one of the groups in which more negative attitudes towards sex offenders could be found and some authors (Craig 2005; Johnson, Hughes and Ireland 2007) realised that in some professional groups working with sex offenders, attitudes could become even more negative after receiving training.

Negative attitudes towards sex offenders might lead to the idea that these inmates deserve to be sexually victimised, inhibiting prison guards from protecting them and preventing their victimisation. Similarly, when sex offenders victimise other inmates they might be considered hypersexualised by prison guards, who decide not to intervene in order to keep stability among these inmates. 


\section{Conclusion}

In conclusion, this study confirms that the majority of guards are aware of the existence of sexual contacts between inmates, and have favourable attitudes towards their prevention, especially when these are associated with victimisation. Furthermore, it shows that, in general, age, professional experience, qualifications or the number of prisons where guards had previously worked does not influence their attitudes. It also demonstrates that guards supervising a more randomly-distributed criminal population have more favourable attitudes towards the prevention of sexual contacts between inmates, mainly when victimisation is involved.

We believe there is a need to increase awareness about individual, institutional and social effects of sexual contacts between inmates. In prison guards' training programmes, a component of attitude evaluation and eventually attitude change should be included on this subject. Evaluation and training should be extended to other professionals and prison administrations, along with the development and implementation of policies aiming at the prevention of sexual contacts between inmates and at intervention with victims and offenders in cases of assault.

Consensual sexual contacts between inmates should also be discussed since these are an individual option which is not formally prohibited but is still risk behaviour from the perspective of individual and institutional safety.

Finally, some constraints of this study should be mentioned and used to make suggestions for future research. It would be useful to include more demographic and professional variables, such as prison guards' sex, religion, job satisfaction and stress, stereotypes and prejudice. Other professionals' attitudes could also be evaluated and, if possible, participation of guards supervising sex offenders should be increased. It would also be interesting to further investigate some issues through the use of qualitative methods or hypothetical situations describing sexual contacts between inmates.

\section{Note}

1 For the 9th grade, students completed their schooling around the age of 15 years and for the 11th grade around the age of 17 years.

\section{References}

Banbury, S. (2004) 'Coercive sexual behaviour in British prisons as reported by adult ex-prisoners', Howard Journal, 43, 113-30.

Corlew, K. (2006) 'Congress attempts to shine a light on a dark problem: an in-depth look at the Prison Rape Elimination Act of 2003', American Journal of Criminal Law, $33,157-90$.

Craig, L. (2005) 'The impact of training on attitudes towards sex offenders', Journal of Sexual Aggression, 11, 197-207.

Crawley, E. and Crawley, P. (2008) 'Understanding prison officers: culture, cohesion and conflicts', in: J. Bennett, B. Crew and A. Wahidin (Eds.), Understanding Prison Staff, Cullompton: Willan. 
Dumond, R. (2000) 'Inmate sexual assault: the plague that persists', The Prison Journal, $80,407-14$.

Eigenberg, H. (1989) 'Male rape: an empirical examination of correctional officers' attitudes toward rape in prison', The Prison Journal, 69, 39-56.

Eigenberg, H. (1992) 'Homosexuality in male prisons: demonstrating the need for a social constructionist approach', Criminal Justice Review, 17, 219-34.

Eigenberg, H. (2000a) 'Correctional officers and their perceptions of homosexuality, rape and prostitution in male prisons', The Prison Journal, 80, 415-33.

Eigenberg, H. (2000b) 'Correctional officers' definitions of rape in male prisons', Journal of Criminal Justice, 28, 435-49.

Eigenberg, H. and Baro, A. (2003) 'If you drop the soap in the shower you are on your own: images of male rape in selected prison movies', Sexuality and Culture, 7, 56-89.

Einat, T. and Einat, H. (2000) 'Inmate argot as an expression of prison subculture: the Israeli case', The Prison Journal, 80, 309-25.

Gear, S. (2007) 'Behind the bars of masculinity: male rape and homophobia in and about South African men's prisons', Sexualities, 10, 209-27.

Gonçalves, R.A. (in press) 'Violence in prison: institutional constraints and inmate's aggressiveness', in: M. Frías-Armenta and V. Corral-Verdugo (Eds.), Bio-PsychoSocial Perspectives on Interpersonal Violence, Hauppage, New York: Nova.

Hensley, C., Koscheski, M. and Tewksbury, R. (2005) 'Examining the characteristics of male sexual assault targets in a southern maximum-security prison', Journal of Interpersonal Violence, 20, 667-79.

Hensley, C. and Tewksbury, R. (2002) 'Inmate-to-inmate prison sexuality: a review of empirical studies', Trauma, Violence and Abuse, 3, 226-43.

Hensley, C., Wright, J., Tewksbury, R. and Castle, T. (2003) 'The evolving nature of prison argot and sexual hierarchies', The Prison Journal, 83, 289-300.

Hogue, T. (1993) 'Attitudes towards prisoners and sexual offenders', in: N. Clark and G. Stephenson (Eds.), Sexual Offenders: Context, Assessment and Treatment, Leicester: The British Psychological Society.

Hsu, H. (2005) 'The patterns of masculinity in prison sociology: a case study in one Taiwanese prison', Critical Criminology, 13, 1-16.

Human Rights Watch (2007) US: Federal Statistics Show Widespread Prison Rape. Available at: http://www.hrw.org/en/news/2007/12/15/us-federal-statistics-show-wide spread-prison-rape (accessed 17 December 2009).

Ibrahim, A. (1974) 'Deviant sexual behaviour in men's prisons', Crime and Delinquency, 20, 38-44.

Johnson, H., Hughes, J. and Ireland, J. (2007) 'Attitudes towards sex offenders, and the role of empathy, locus of control and training: a comparison between a probationer police and general public sample', The Police Journal, 80, 28-54.

Jones, T. and Pratt, T. (2008) 'The prevalence of sexual violence in prison: the state of the knowledge base and implication for evidence-based correctional policy making', International Journal of Offender Therapy and Comparative Criminology, 52, 280-95.

Knowles, G. (1999) 'Male prison rape: a search for causation and prevention', Howard Journal, 38, 267-82.

Kury, H. and Smartt, U. (2002) 'Prisoner-on-prisoner violence: victimization of young offenders in prison: some German findings', Criminal Justice, 2, 411-37.

Man, C. and Cronan, J. (2001) 'Forecasting sexual abuse in prison: the prison subculture of masculinity as a backdrop for "deliberate indifference", Journal of Criminal Law and Criminology, 92, 127-85.

Moster, A. and Jeglic, E. (2009) 'Prison warden attitudes toward prison rape and sexual assault: findings since the Prison Rape Elimination Act (PREA)', The Prison Journal, 89, 65-78. 
Nacci, P. and Kane, T. (1983) 'The incidence of sex and sexual aggression in federal prisons', Federal Probation, 47, 31-6.

Salas, A. (2001) 'Consecuencias de la prisionización [Consequences of imprisonment]', Revista Cenipec, 20, 9-22.

Saum, C., Surratt, H., Inciardi, J. and Bennett, R. (1995) 'Sex in prison: exploring the myths and realities', The Prison Journal, 75, 413-30.

Struckman-Johnson, C., Struckman-Johnson, D., Rucker, L., Bumby, K. and Donaldson, S. (1996) 'Sexual coercion reported by men and women in prison', Journal of Sex Research, 33, 67-76.

Struckman-Johnson, C. and Struckman-Johnson, D. (2000) 'Sexual coercion rates in seven midwestern prison facilities for men', The Prison Journal, 80, 379-90.

Tewksbury, R. (1989) 'Measures of sexual behaviour in an Ohio prison', Sociology and Social Research, 74, 34-9.

Tewksbury, R. and West, A. (2000) 'Research on sex in prison during the late 1980s and early 1990s', The Prison Journal, 80, 368-78.

Wolff, N., Blitz, C., Shi, J., Bachman, R. and Siegel, J. (2006) 'Sexual violence inside prisons: rates of victimization', Journal of Urban Health, 83, 835-48.

Date submitted: April 2010

Date accepted: May 2010 